\title{
MOTIVAÇÕES E EXPECTATIVAS DE MULHERES EM SITUAÇÃOO DE VIOLÊNCIA NO MOMENTO DA DENÚNCIA EM UMA DELEGACIA ESPECIALIZADA EM ATENDIMENTO À MULHER
}

MOTIVATIONS AND EXPECTATIONS OF WOMEN IN SITUATIONS OF VIOLENCE WHEN FILING A COMPLAINT AT A POLICE STATION SPECIALIZED IN ASSISTANCE TO WOMEN MOTIVACIONES Y EXPECTATIVAS DE MUJERES EN SITUACIÓN DE VIOLENCIA EN EL MOMENTO DE LA DENUNCIA EN UNA COMISARÍA ESPECIALIZADA EN ATENCIÓN A LA MUJER

\author{
Bruna Maffei* \\ Cristiane Barros Marcos ${ }^{* *}$ \\ Simone dos Santos Paludo ${ }^{* * *}$
}

\begin{abstract}
RESUMO
O estudo busca compreender os motivos que levam as mulheres em situação de violência a buscar ajuda em uma Delegacia de Polícia Especializada de Atendimento à Mulher (DEAM) e suas expectativas após a denúncia. A coleta de dados foi realizada durante o plantão psicológico na DEAM, em uma cidade no Sul do Brasil, por meio de uma entrevista semiestruturada. Os dados de 24 acolhimentos a mulheres com idade entre 19 e 84 anos $(\mathrm{M}=36,86 ; \mathrm{dp}=15,90)$ foram submetidos à análise qualitativa. $\mathrm{O}$ excompanheiro foi o principal agressor; e a violência psicológica e física, os principais motivos para as mulheres procurarem a delegacia. Todas buscaram a polícia na expectativa de resolutividade do serviço jurídico, principalmente com medidas de segurança. $\mathrm{O}$ estudo evidencia a necessidade do fortalecimento da rede de atenção social, de saúde e de justiça, auxiliando na revelação da violência e no desenvolvimento de novas perspectivas futuras após o ocorrido.
\end{abstract}

Palavras-chave: Violência contra as mulheres. Denúncia. Delegacia Especializada de Atendimento à Mulher (DEAM).

\footnotetext{
Texto recebido em 25 de agosto de 2016 e aprovado para publicação em 14 de junho de 2018.

"Psicóloga, residente do Programa de Residência Multiprofissional em Atenção à Saúde do Hospital Escola da Universidade Federal de Pelotas (Ufpel).E-mail: brunamaffei15@hotmail.com.

"* Mestra em Psicologia, professora assistente na Universidade Federal do Rio Grande (FURG). Endereço: Rua Visconde de Paranaguá, 102 - Centro, Campus Saúde, Rio Grande-RS, Brasil. CEP: 96203-900. E-mail: cristianemarcos@gmail.com.

** Doutora em Psicologia, professora associada na FURG, docente no Programa de Pós-Graduação em Saúde Pública da FURG. Endereço: Avenida Itália, km 8 - Prédio da Psicologia, Campus Carreiros, Rio Grande-RS, Brasil. CEP: 96203-900. E-mail: simonepaludo@furg.br.
} 


\section{ABSTRACT}

The study aims to understand the reasons that drive women in situations of violence into looking for help from a Police Station Specialized in the Assistance to Women (DEAM - in Portuguese) and the women's expectations after filing a complaint. Data collection was carried out through a semi-structured interview during a psychological emergency attendance duty at one of these specialized police stations in a city in the South of Brazil. The data collected in 24 cases with women from 19 to 84 years (Avg $=36.86 ; s d=15.90)$ were subjected to qualitative analysis. The former partner was appointed as the main aggressor; and psychological and physical violence were the main reasons leading the women into looking for help from a Police Station. All women looked for the DEAM with the expectation that the legal system could solve their problems, mainly through security measures. This study shows that there is a need to empower the social care, health and justice network, helping to unveil violence and develop new perspectives after the event.

Keywords: Violence against women. Complaint. Police Station Specialized in the Assistance to Women (DEAM).

\section{RESUMEN}

El estudio busca comprender las razones que llevan a las mujeres en situación de violencia a buscar ayuda en una Comisaría Especializada en Atención a la Mujer (DEAM) y sus expectativas después de la denuncia. Los datos fueron obtenidos durante el servicio psicológico en la DEAM en una ciudad del sur de Brasil, a través de una entrevista. Las 24 mujeres del estudio, de 19 a 84 años $(M=36.86, S D=15.90)$, fueron sometidas a un análisis cualitativo. El ex compañero fue nombrado como el agresor principal y la violencia psicológica y física fueron los principales motivos que llevaron a las mujeres a la DEAM. Todas las mujeres buscaron a la DEAM con la esperanza de resolver el problema, principalmente con medidas de seguridad. El estudio demuestra la necesidad de fortalecimiento de la red de atención social, salud y justicia, ayudando en la exposición de la violencia y en el desarrollo de nuevas perspectivas futuras.

Palabras clave: Violencia contra las mujeres. Denuncia. Comisaría Especializada en Atención a las Mujeres (DEAM). 


\section{INTRODUÇÃO}

violência contra a mulher é um fenômeno universal e pode ser perpetrada
em suas distintas formas (física, psicológica, sexual, moral e patrimonial)
e envolve a inter-relação de condições multifatoriais (individuais, sociais,
culturais e históricas). Dados da Organização Mundial de Saúde indicam que
cerca de 35\% das mulheres no mundo já passaram por algum tipo de violência
física ou sexual em algum momento das suas vidas (World Health Organization,
2013). Devido a sua magnitude, a violência contra a mulher tem sido
compreendida como uma questão de saúde pública e de violação dos direitos
humanos (Silva, Coelho, \& Caponi, 2007).

No Brasil, a literatura científica tem buscado retratar a realidade vivenciada por mulheres em diferentes localidades. Barros et al. (2016) investigaram a violência cometida por parceiro íntimo aplicando o instrumento de autorrelato denominado World Health Organization Violence Against Women (WHO VAW) em 245 mulheres de uma comunidade de Recife, Estado de Pernambuco, com idades entre 15 e 49 anos, e encontraram uma prevalência de 52,7\% de violência emocional, $46,1 \%$ de violência física e $13,6 \%$ de violência sexual. $\mathrm{O}$ referido instrumento foi validado para o Brasil por Schraiber, Latorre, França Júnior, Segri, \& D’Oliveira (2010) e, no processo de validação, os pesquisadores acessaram 940 mulheres da cidade de São Paulo e 1.188 moradoras de 15 municípios da Zona da Mata de Pernambuco, e evidenciaram que as mulheres da zona rural estavam mais vulneráveis a situaçóes de violência visto que referiram com maior frequência ter sofrido pelo menos uma forma de violência por parceiro íntimo (46,4\% na zona urbana e 54,2\% na zona rural).

Há de se ter cautela ao se presumir maior prevalência de qualquer tipo de violência à mulher pela região, tendo em vista os diferentes casos de mulheres que não revelam os episódios, que não realizam denúncia e aquelas que recorrem a diferentes recursos que não a busca pela delegacia (Romagnoli, Abreu, \& Silveira, 2013). Outro motivo se refere ao fato de que as mulheres em situação de violência ainda têm uma representação depreciativa sobre si mesmas, que, na maioria das vezes, é resultado da má compreensão do processo de violação sofrido e do poder masculino construído historicamente (Fonseca, Ribeiro, \& Leal, 2012). As mulheres comumente sentem-se culpadas, envergonhadas e frágeis diante dos episódios de violência, aumentando, assim, o tempo de exposição a tais situações e, consequentemente, o tempo entre o ocorrido e sua publicização. 
A promulgação da Lei no 11.340/2006, conhecida como a Lei Maria da Penha, teve papel importante na visibilidade das agressões contra a mulher, visto que o tema passou a ser de interesse público, e a proteção, responsabilidade do Estado (Romagnoli, 2015). A criação das Delegacias Especializadas de Atendimento à Mulher (DEAM), as medidas mais rigorosas impostas aos agressores e as açôes dos serviços de saúde e da assistência parecem ter motivado as mulheres a procurar ajuda (Meneghel, Mueller, Collaziol, \& Quadros, 2013).

O perfil das mulheres que buscam apoio nas delegacias tem sido divulgado pela análise dos dados obtidos nas denúncias. Romagnoli, Abreu e Silveira (2013) analisaram 1.315 boletins de ocorrência no período de 2007 a 2009, feitos por mulheres em situação de violência no $10^{\circ}$ Batalhão da Polícia Militar em Montes Claros, Estado de Minas Gerais, e evidenciou que 62,6\% dos registros referiamse à ocorrência de violência física. Já outro estudo baseado em 103 ocorrências de mulheres que buscaram a Delegacia de Polícia Civil na Região Noroeste do Rio Grande do Sul revelou maior prevalência de violência psicológica $(86,5 \%)$, seguida de violência física $(44,2 \%)$, sendo o agressor, na maioria das vezes, o parceiro íntimo ou ex-parceiro (Griebler \& Borges, 2013).

Esses dados possivelmente não refletem a real situação do país, uma vez que a vergonha e o medo ainda são obstáculos importantes para a revelação e o registro na DEAM, mas evidenciam que as mulheres estão expostas a diversos tipos de violência. A busca pela DEAM por mulheres em situação de violência é uma das principais portas de entrada no acesso a políticas públicas no combate a violência (Oliveira \& Moreira, 2016). Dessa forma, a procura pela DEAM pode ser o primeiro passo para a articulação de um trabalho efetivo na área da Justiça, da Saúde e da Assistência Social. Embora existam pesquisas sobre o perfil das mulheres que acessam a DEAM (Carneiro \& Fraga, 2012; Griebler \& Borges, 2013; Romagnoli et al., 2013), ainda são desconhecidas as principais motivações e as expectativas sobre o serviço oferecido pelo sistema de segurança. Assim, este estudo teve como objetivo compreender os motivos que levam as mulheres a buscar ajuda na DEAM e suas expectativas após a denúncia.

\section{MÉTODO}

Delineamento e contexto do estudo: trata-se de uma pesquisa descritiva e de natureza qualitativa. Optou-se pela abordagem qualitativa por possibilitar compreender o fenômeno na perspectiva do sujeito, de acordo com seus significados, crenças, valores e motivaçôes que englobam sua realidade social (Minayo, 2015). O estudo foi desenvolvido em parceria com a DEAM na cidade 
do Rio Grande, na Região Sul do País, por meio do projeto intitulado "Plantão Psicológico na DEAM”. Os plantóes aconteceram duas vezes por semana, dentro da própria delegacia, e tinham o objetivo de acolher e oferecer um espaço de escuta às mulheres que ali chegavam. A modalidade de plantão foi escolhida para contemplar as necessidades das mulheres e da própria delegacia, que não contava com um profissional da Psicologia, e seguiu as orientações presentes na literatura, que sugere que os plantôes psicológicos aconteçam em períodos preestabelecidos, visando à escuta empática e cuidadosa no momento em que a pessoa necessita ou que está em sofrimento (Mahfoud, 1987; Scorsolini-Comin, 2015). A cidade onde foi realizado este estudo está localizada no extremo litoral sul do Estado do Rio Grande do Sul. Tem cerca de 200 mil habitantes e tem como principal meio econômico o setor portuário. A rede de assistência à mulher conta atualmente com uma DEAM, Defensoria Pública, um Centro de Referência de Assistência Social (CRAS), um Centro de Referência Especializado de Assistência Social (CREAS), uma Coordenadoria Municipal de Políticas Públicas para as Mulheres e uma Casa de Passagem.

Participantes: entre as 27 mulheres em situação de violência que foram atendidas no projeto "Plantão Psicológico", 24 aceitaram ceder as informações coletadas durante o acolhimento para o estudo, mediante assinatura do termo de consentimento. Portanto este estudo contou com dados de 24 acolhimentos.

Instrumentos e procedimentos: para a coleta de dados, foi utilizada uma ficha de dados sociodemográficos e um entrevista semiestruturada com as seguintes questôes norteadoras: "Qual o motivo da procura à Delegacia da Mulher?"; "Você considera ter sofrido algum tipo de violência?"; "Como você se sente vivenciando essa(s) violência(s)?”; "Qual sua percepção sobre o que ocorreu?”; "Você deseja registrar um boletim de ocorrência?"; "O que você espera da Delegacia?"; "Como você enfrenta ou pensa em enfrentar a situação que está vivenciando?”; "Qual sua perspectiva futura após o ocorrido?”. Foi privilegiada a entrevista qualitativa semiestruturada por considerar que essa estratégia poderia promover um espaço para a expressão de experiências, crenças e emoções (Moré, 2015), e garantir flexibilidade com o uso do roteiro de perguntas (Sampieri, Colado, \& Lucio, 2013). Os dados obtidos foram gravados, transcritos e armazenados em registros de campo. Esses registros se constituem importantes para anotaçôes das histórias das participantes e de dados pessoais e dificuldades ao longo do processo de pesquisa (Sampieri, Colado, \& Lucio, 2013).

Procedimentos éticos: o estudo obteve a aprovação do Comitê de Ética em Pesquisa na Área da Saúde da Universidade, sob o Parecer n.o 106/2014, e, em seguida, pelas autoridades locais da DEAM. A pesquisa ainda foi fundamentada 
nas Diretrizes e Normas Regulamentadoras de Pesquisas Envolvendo Seres Humanos, conforme a Resolução do Conselho Nacional de Saúde n.o 466 de 2012. Para todas as mulheres que foram acolhidas no plantão, foi feito o convite para a utilização dos dados coletados no serviço. Àquelas que aceitaram ceder suas informações foi entregue um termo de consentimento livre e esclarecido. Aquelas que não concordaram tiveram seus dados excluídos da pesquisa sem qualquer prejuízo a ela ou a seu acolhimento.

Análise dos dados: todos os dados coletados foram submetidos à análise de conteúdo categorial temática, proposta por Minayo (2015), a qual é composta por três etapas:

a) a organização dos dados por meio de leituras exaustivas;

b) a análise propriamente dita, norteada pelos objetivos da pesquisa; e

c) a identificação dos núcleos de sentido. Com base nesses núcleos, foram criadas categorias.

Dessa forma, foram lidos os escritos, as transcrições e desmembradas as informações. Conforme surgiram semelhanças e, ou, repetições, foram criadas categorias para os significados relatados pelas mulheres em situação de violência.

\section{RESULTADOS E DISCUSSÃO}

Os resultados estão apresentados de acordo com os 6 núcleos de sentido principais e as 17 categorias, como consta no quadro 1.

\section{Quadro 1 - Núcleos de sentido e suas respectivas categorias}

\begin{tabular}{|c|c|}
\hline Núcleos de sentido & Categorias \\
\hline 1. Características da violência & $\begin{array}{l}\text { 1.1 Tipo de violência } \\
\text { 1.2 Relação com o agressor } \\
\text { 1.3 Tempo de violência }\end{array}$ \\
\hline 2. Motivo da busca à DEAM & $\begin{array}{l}\text { 2.1 Violência psicológica } \\
2.2 \text { Violência física } \\
2.3 \text { Ameaça a familiares }\end{array}$ \\
\hline
\end{tabular}




\begin{tabular}{|l|l|}
\hline 3. Percepção da violência sofrida & $\begin{array}{l}3.1 \text { Sentimento de vergonha } \\
3.2 \text { Sentimento de culpa }\end{array}$ \\
\hline 4. Expectativas referentes à lei e à Justiça & $\begin{array}{l}1.1 \text { Resolutividade por medida prote- } \\
\text { tiva } \\
1.2 \text { Resolutividade pela punição ao } \\
\text { agressor }\end{array}$ \\
\hline 5. Estratégias de enfrentamento & \begin{tabular}{l}
5.1 Recorrer a familiares \\
5.2 Recorrer a serviços e, ou, \\
profissionais \\
5.3 Fé \\
5.4 Apoio nos filhos \\
\hline 6. Perspectivas de futuro
\end{tabular} \\
& $\begin{array}{l}6.1 \text { Cuidado maternal } \\
6.2 \text { Viver em paz } \\
6.3 \text { Permanecer sem companheiro }\end{array}$ \\
\hline
\end{tabular}

Fonte: elaborado pelas autoras.

\subsection{Caracterização dos participantes}

As mulheres que procuraram espontaneamente a DEAM tinham idades entre 19 e 84 anos $(M=36,6 ; \mathrm{dp}=15,90)$, das quais 11 eram solteiras, 6 viviam em união estável, 3 eram separadas, 2 casadas e 2 viúvas. Quanto ao número de filhos, 17 mulheres tinham entre 1 e 3 filhos. O nível de escolaridade variou desde o ensino fundamental incompleto até ensino superior incompleto. Com relação ao número de denúncias, 15 mulheres informaram que aquela era a primeira; 7 informaram ser a segunda; 1 , a terceira; e 1, a sexta denúncia.

\subsection{Características da violência}

\subsubsection{Tipo de violência, relação com parceiro e tempo de violência}

As 24 mulheres relataram ter sofrido múltiplas formas de violência, sendo que todas informaram ter vivenciado a violência psicológica, 20 notificaram também violência física, 6 violência patrimonial e 4 violência sexual. Como forma de assegurar o anonimato das mulheres que participaram do estudo, elas serão 
identificadas por um número de 1 a 24, de acordo com a ordem de acolhimentos realizados.

$\mathrm{Na}$ maioria das vezes, a violência foi perpetrada pelo ex-companheiro (12 casos) ou companheiro (10 casos). Os outros dois casos envolveram agressões cometidas pela sogra e cunhada, e pelo filho e nora. O tempo de relação com os agressores variou de 6 meses a 30 anos, e o tempo de vivência de situações de violência na relação foi de 1 semana a 8 anos. Do total de mulheres acolhidas, apenas uma decidiu não fazer o boletim de ocorrência após o acolhimento.

Essas informações sugerem que as mulheres sofrem, diariamente, diversos tipos de violência, e o acúmulo e intensificação das agressões torna a situação insuportável, provocando a busca por apoio, como nas falas das mulheres em situação de violência que foram entrevistadas: "Eu cheguei no meu limite. Eu não aguento mais. Eu tô totalmente infeliz com uma pessoa dessas. Eu já dei várias oportunidades pra ele, de tanto ele me ameaçar" (A18). "Não vou dizer pra ti que ele vá mudar, porque ele não vai mudar [. . .]. A minha vida toda com ele, eu achei que ele ia mudar, ia mudar, e ele não mudou" (A2). "Se ele não mudou em dois anos nessas idas e voltas, não muda mais" (A17).

É possível constatar que muitas mulheres permaneceram expostas às situações de violência por um longo tempo, investindo seus esforços na busca da relação afetiva e, ou, positiva que, em algum momento, tiveram com seus parceiros. Tais comportamentos são comuns durante o ciclo de violência, quando existe uma idealização do parceiro e uma expectativa de mudança (Lucena et al., 2016).

Outro aspecto que chama atenção é o fato de que a maioria delas (15 mulheres) estava realizando a denúncia pela primeira vez, mesmo já tendo vivenciado a violência por muito tempo. Esse dado permite refletir sobre os impactos na saúde da mulher. Mendonça e Ludermir (2017) encontraram altos índices de transtornos mentais comuns, como irritabilidade, fadiga, insônia, dificuldade de concentração e queixas somáticas relacionadas à depressão e ansiedade, em mulheres que relataram violência perpetrada por parceiro íntimo, em especial, violência psicológica.

Os relatos também reforçam que as mulheres não denunciam logo a primeira agressão. Elas procuram a delegacia depois de recorrentes violências, sendo que, após o primeiro registro, possivelmente outros aconteçam (Sagim, Biasoli-Alvez, Delfino, \& Vanturini, 2007). A dificuldade na realização da denúncia, entre outros motivos, deve-se ao medo construído por meio de ameaças e agressões, não apenas à mulher, mas a pessoas próximas, o que faz com que elas se refugiem no silêncio até decidirem pelo rompimento das violaçôes, evidenciando as etapas 
do ciclo da violência descrito por Lucena et al. (2016). Embora varie de acordo com o funcionamento e singularidades de cada casal, de um modo geral, esse ciclo funciona como um sistema circular, devido sua repetição ao longo do tempo, passando por fases que giram em torno da tensão (insultos e intimidações), da agressão e da reconciliação. A mulher vive uma constante ambivalência entre as violações sofridas e a idealização do parceiro, e esperança de mudança. $\mathrm{O}$ ciclo, ao contrário do que a mulher acredita, não acaba, muitas vezes, sendo periódico, gerando um movimento que passa novamente por todas as fases, intensifica-se ao longo do tempo e tende a diminuir o período entre as ocorrências (Ministério da Saúde, 2011).

\subsection{Motivos da busca à DEAM}

\subsubsection{Violência física e psicológica}

Diante das recorrentes violências perpetradas ao longo do ciclo de violência, existem vários motivos concomitantes que levam a mulher a procurar a DEAM para realizar a denúncia. Desses, a violência psicológica seguida da violência física foram os mais prevalentes entre as mulheres deste estudo, sendo que esses dois tipos de violência tendem a ocorrer simultaneamente, como nos seguintes trechos apontados pelas mulheres em situação de violência acolhidas na DEAM: "Ele diz que até vai sair da minha casa, mas que primeiro ele vai me matar e me esquartejar" (A10). "Todos os dias, de manhã, ele me bate de cabo de vassoura. Aí, quando ele foi no fogão e dizia que ia me jogar uma água quente, aí eu desesperei e saí correndo" (A7). "Passou a mão no vidro, me ameaçando que, se eu não era mais dele, então não ia ser de ninguém" (A12). "Cheguei em casa, ele pegou a chave comigo na minha bolsa e me espancou. Isso não é a primeira vez que ele me bate" (A21). "Ela (cunhada) puxou meu cabelo, me deu socos" (A5).

\subsubsection{Ameaça a familiares}

Onze mulheres romperam o silêncio e procuraram a DEAM no momento em que a ameaça se estendeu a algum familiar, conforme seus relatos: "Ele passou de mão numa taquara, pra dar nela (filha), e deu nela [...]. Ela tá lá no ambulatório, porque acho que fraturou a mão [. . .]. Ele partiu pra cima da minha filha. Não foi só o fato dele pegar um vidro e partir pra cima de mim" (A12). "Ele sempre me bateu, e eu nunca dei parte, porque tenho medo [. . .]. Só que, nessa última vez, ele bateu em mim e na minha filha. [. . .] Em mim, é uma coisa, eu vou 
sofrer, vai doer, vai passar. Agora, nos meus filhos, não" (A15). "Eu só não vim antes porque eu tava apavorada, porque ele me ameaçava que ia me matar, que ia matar meu filho (A18)".

Os dados sugerem casos em que as mulheres se mantêm na violência enquanto esta é perpetrada contra elas. Elas acreditam conseguir suportar sozinhas a situação, mas a possibilidade de ferir outra pessoa não é tolerada. Da mesma forma que os filhos podem ser um motivo de permanência da mulher com o agressor, a exposição dos filhos ao perigo pode ser um fator determinante no rompimento desse ciclo. Os dados levam a crer que os filhos e demais familiares, quando expostos ao agressor, passam a ser mais uma vítima desse contexto.

As situações de violência, portanto, podem ocorrer de forma progressiva e silenciosa, tornando-se gradativamente mais manifesta como violação dos direitos humanos. Por vezes, as mulheres não entendem essas açôes como violência, mas, por sua recorrência e intensificação, passam a melhor compreender os agravos físicos e psicológicos à sua saúde (Silva et al., 2007). Com a continuidade do ciclo de violência, as mulheres podem iniciar um processo de questionamento sobre as recorrentes promessas de mudanças por parte do agressor. Mesmo sendo um processo complexo e doloroso, as sucessivas desilusões podem ser um motivador da procura pela DEAM.

\subsection{Percepção da violência sofrida}

\subsubsection{Sentimento de vergonha}

Quando questionadas sobre a percepção da violência sofrida, a maioria das mulheres acolhidas percebeu que a situação vivenciada lhes causou constrangimento, como nestes relatos: "Pra mim, é uma vergonha. Pra ele, ele acha bonito" (A15). "Eu passava vergonha [. . .] Ainda mais no meio da rua, né?" (A13). "Eu tenho medo que ele me encontre na rua e me bata na frente dos outros. Pra mim, é uma vergonha" (A14). "Até no Facebook, ele bota que me tirou da zona. Que vergonha! Ainda marca todo mundo pra ver" (A19). "O desrespeito que ele tem comigo, porque a gente conviveu cinco anos, não foi cinco meses" (A20).

A vergonha ainda é a percepção mais recorrente entre mulheres em situação de violência (Fonseca et al., 2012), sendo que, associada ao medo da exposição social, favorecem a ocultação da violência. Como pode ser visto na fala de uma das mulheres acolhidas: "Ele me fazia passar vergonha [. . . Eu nunca falei nada disso pra ninguém, por vergonha” (A20). O silêncio traz, em muitos casos, o 
sofrimento em suportar as intimidações. As mulheres aprendem, desde muito jovens, que é preferível suportar a dor a procurar ajuda em serviços especializados, assim como são ensinadas a não contar a outras pessoas por vergonha (Sagim et al., 2007). A dinâmica da violência está envolta em silêncios, segredos e controle da relação violenta. Esses elementos podem dificultar o conhecimento dos familiares, amigos e pessoas em geral, do ciclo de violência que está sendo mantido (Diniz \& Angelim, 2003).

Quando a mulher busca a DEAM, está disposta a tornar público o que, até então, era considerado privado e invisível. A denúncia, contudo, não dá visibilidade apenas à violência sofrida. Expõe a própria fragilidade e as escolhas realizadas até o momento. A exposição associada ao relato de situações pessoais e dolorosas para alguém desconhecido, como a um policial, torna ainda mais delicada a procura por ajuda. O policial ainda representa uma figura intimidadora e, por vezes, não recebe o preparo adequado para realizar o acolhimento. Oliveira e Moreira (2016) acreditam que a procura pela DEAM pode ser influenciada pela forma como as mulheres serão acolhidas nesse serviço, o que pode interferir positiva ou negativamente na maneira como elas superarão o ciclo de violência. Nesse sentido, as autoras reforçam a importância da formação continuada entre os profissionais da DEAM, como forma de prestar o melhor atendimento às mulheres e possibilitar um espaço de discussões acerca das repercussões subjetivas no cotidiano de sua atuação.

\subsubsection{Sentimento de culpa}

Os relatos das mulheres deste estudo revelam ainda uma relação hierárquica, na qual é a mulher quem tem de se sentir envergonhada perante esses ocorridos. A intimidação que o agressor exerce só faz reforçar seu poder. Entende-se, assim, uma diferença da percepção do homem e da mulher sobre o mesmo ato. A culpa foi exposta por duas participantes: "Eu me culpo por ter deixado ele entrar na minha casa [... . Eu prejudiquei a minha filha" (A12). Dessa forma, a revelação parece legitimar uma série de escolhas erradas que, quando descobertas, geram culpa e constrangimento, reforçando o estereótipo de que as mulheres são responsáveis pelos crimes cometidos contra elas. Por vezes, os próprios profissionais das delegacias que acolhem os relatos reiteram esse julgamento, esquecendo que foi o afeto, e não a violência, o que uniu aquela mulher ao parceiro.

Oliveira e Moreira (2016) destacam que as atitudes dos policiais podem reproduzir preconceitos, posturas sexistas e julgadoras que de nada contribuem para interromper as ações violentas delatadas ali. As autoras sugerem que existe um atendimento diferenciado quando os profissionais percebem interesse e 
determinação por parte da mulher na interrupção da violência, atribuindo a ela o poder de decisão pela continuação ou não da violência. Tais fatos revelam que "Ainda que a Justiça aja em favor da proteção das mulheres e contra a violência, continua sendo das mulheres a responsabilidade por reconhecer o risco que estão correndo e, conscientes disso, manterem-se afastadas daqueles que as agrediram" (Oliveira \& Moreira, 2016, p. 739).

\subsection{Expectativas referentes à lei e à Justiça}

\subsubsection{Resolutividade por medida protetiva}

A análise dos relatos relacionados às expectativas sobre a denúncia (registro de ocorrência na DEAM) evidenciou uma única categoria: a resolutividade. Todas as mulheres manifestaram o desejo de que a DEAM resolvesse seu problema, seja pela medida protetiva e, ou, da garantia de segurança (21 casos) e da punição ao agressor (5 casos). Os relatos estiveram, em sua maioria, voltados para a necessidade de proteção, como na fala de uma mulher: "Só quero uma proteção, que ele veja que agora ele não pode chegar mais perto de mim, que eu tenho certeza que ele vai se assustar" (A9).

A denúncia inverte a relação de poder até então existente. Agora é a mulher quem pode ameaçar e punir seu agressor. Sentimentos ambivalentes podem emergir nesses momentos, pois o desejo da mulher é que a agressão acabe e não necessariamente que a relação com o agressor termine. Quando o vínculo emocional ainda existe, há um receio de realizar a denúncia pelo medo que o companheiro ou ex-companheiro seja detido. "Se eu ver que não adiantou e que ele anda na volta, aí pode ir pra cadeia" (A9). "Desejo que ele seja preso, mesmo não querendo que chegasse a esse ponto" (A3). Essa situação revela que a mulher se sente responsável também pelo desdobramento da denúncia, como se a possibilidade de uma punição derivasse apenas da sua denúncia e não do ato do agressor.

Outro significado emergente nos relatos se refere à solicitação de defesa. As mulheres veem a Lei Maria da Penha como uma forma de alcançar seus direitos e garantir sua proteção (Vieira, Padoin, Souza, \& Paulo, 2011), mas têm dúvidas sobre a efetividade desta. "Não adianta eu chegar lá e mostrar papelzinho pra ele e não ir ninguém lá, e ele passar uma faca no meu pescoço. Depois dele me matar, já era" (A10). Isso gera uma descrença nos serviços de Justiça e, consequentemente, a sensação de desamparo por parte da mulher, que acreditava que a denúncia fosse romper com o ciclo de violência (Santi, Nakano, \& Lettiere, 2010). Meneghel, 
Mueller, Collaziol e Quadros (2013) destacam que os próprios operadores da lei identificam limitaçôes na aplicação da lei, evidenciando que o Estado ainda não consegue oferecer total segurança à mulher.

A expectativa da mulher por resolutividade por parte da DEAM implica acreditar no compromisso de ação por parte desse serviço. Cabe considerar que a denúncia, por si só, é uma postura ativa da mulher para a mudança, mas não é a única. É necessário que a mulher seja vista como componente fundamental para sua saída do ciclo de violência. Para que isso aconteça, é imprescindível que ela tenha respaldo assistencial, psicológico e jurídico para o enfrentamento das etapas subsequentes, levando em consideração a complexidade de afetos e pensamento envoltos na sua relação com o agressor.

\subsubsection{Resolutividade pela punição ao agressor}

O medo do não cumprimento da medida e o reconhecimento das limitações acabam por gerar outras expectativas entre as mulheres que realizam a denúncia. Quando não conseguem encontrar outra saída para a violação sofrida, elas desejam a punição do agressor: "Que o sistema jurídico prenda ele" (A12). "Botem uma prensa nele. Que faça alguma coisa, e que ele não faça mais" (A7). "Eu quero, assim, que eu dê parte dele e que ele seja punido por isso [. . . ou ele responda um processo, trabalho comunitário [. . . ], de repente, eu dando uma punição pra ele, ele vai aprender uma lição [. . .], mesmo que ele não vá mudar. Porque eu sei que ele não vai mudar" (A20). Ainda, o desejo de punição do agressor está muito atrelado ao medo de novas agressóes e ameaças (Santi et al., 2010).

A denúncia é apenas o primeiro passo de um processo policial e judicial que se seguirá. Esse processo é desconhecido por parte das mulheres que realizam a denúncia, o que torna fundamental os esclarecimentos do processo por parte da equipe da DEAM (Oliveira \& Moreira, 2016).

\subsection{Estratégias de enfrentamento}

\subsubsection{Recorrer a familiares}

Ao questionar-se como as mulheres estavam enfrentando o momento da violência e da denúncia, 18 afirmaram uma postura proativa e mencionaram que recorrem à ajuda familiar: "Minha mãe é muito minha amiga [. . .]. Eu conto as coisas pra ela, tudo. Ela me dá apoio, fica do meu lado, ela me dá força, ela 
me incentiva" (A14). As figuras da mãe e do filho foram citadas por 6 mulheres, enquanto os amigos foram referidos por 4 mulheres.

Em situações de violência, as mulheres inicialmente tendem a procurar sua rede de apoio mais próxima (Santi et al., 2010), como a família e amigos, considerados recursos importantes na estratégia de enfrentamento (Lettiere \& Nakano, 2011). Uma possível explicação é que elas recorram a pessoas com as quais tenham maior vínculo e se sintam mais confortáveis em expor experiências particulares, visto o medo de serem culpabilizadas.

\subsubsection{Recorrer a serviços e, ou, profissionais}

A busca das mulheres deste estudo pela DEAM também é entendida como uma forma de enfrentamento, ou seja, recurso utilizado para romper com a violência sofrida. "A gente agora tem essa Delegacia da Mulher, a gente pode se defender" (A20). A Polícia Militar foi acionada por 6 mulheres no momento da violência. O Disque 100, o psicólogo, o psiquiatra, o CRAS e o Conselho Tutelar também foram mencionados, mas apenas por uma mulher. Evidencia-se, dessa forma, que a procura inicial ocorre principalmente no sistema de Justiça, possibilitando inferir que compreendem a violência contra mulher apenas como um problema de polícia e, ou, segurança pública, e não de saúde. A DEAM é, sem dúvida, a porta de entrada para a revelação das situações de violência e deve garantir o fluxo de proteção da mulher por meio de ações intersetoriais. Não existe uma hierarquia das áreas que protegem mulher (segurança, assistência, saúde), todas precisam estar articuladas. Contudo é necessário que tais questôes sejam reconhecidas também pelas mulheres, uma vez que a maioria acredita que quem precisa de acompanhamento psicológico ou de atendimento de saúde é o agressor. Para as mulheres do estudo, apenas a DEAM pode ajudá-las. Lettiere e Nakano (2011) já destacavam que a busca por serviços depende da gravidade da situação a que a mulher é exposta e das consequências físicas e psicológicas.

\subsubsection{Fé}

A fé também foi citada como meio utilizado para tentar suportar as violências. "Sozinha não, porque eu tenho Deus e Jesus" (A11).

Sozinha, modo de dizer. Ficar com meus filhos e Deus [. . .] Eu não frequento a Igreja, também não frequento sessão. Deus é acima de tudo. Ele sempre olha pra baixo pela gente [... . . Deus nunca dá um fardo que tu não possa carregar [. . . . Sempre confiando que um dia Deus ia me ajudar a sair e a reagir (A20). 
As falas apontam que a fé e a religião oferecem suporte às situações vividas (Lettiere \& Nakano, 2011). A participação em cultos ou grupos religiosos pode aumentar a chance de construção da rede de apoio social e, consequentemente, torná-la mais fortalecida para a busca da DEAM. Contudo também podem aumentar o risco de exposição, visto que algumas crenças colocam a mulher em um lugar passivo como, a ideia de que existem alguns "fardos" que precisam ser suportados. O período de sofrimento vivenciado pelas mulheres também aparece como vontade de "Deus", no sentido de que elas precisavam passar por isso devido a um desejo maior. Esses dados reforçam a ideia de culpabilização da mulher em situação de violência e reflete crenças e ideologias nas quais está imersa.

\subsubsection{Apoio nos filhos}

As mulheres buscaram consolo e amparo também nos filhos. Como nos relatos das mulheres: "Eu buscava nos meus filhos, porque eles são tudo pra mim. Então foi na força que eu vi neles que procurei ajuda, também porque, senão, eu acho que eu tava até hoje se não fosse por eles mesmo" (A17); "Eu tenho medo, se eu não for forte, quem vai cuidar dos meus filhos?" (A15). Esses foram fundamentais para que elas se mantivessem fortes diante das violaçôes sofridas. Mesmo os filhos sendo motivo de suporte para continuarem fazendo planos, as falas reforçam os papéis sociais em que a mulher está inserida e seu papel de cuidado materno, doméstico e de responsabilidade com os demais membros da família (Fonseca et al., 2012).

\subsection{Perspectivas de futuro}

\subsubsection{Cuidado materno}

A denúncia da violência parece potencializar o desejo de mudanças e faz com que as mulheres se permitam ter outros planos, vislumbrando uma nova etapa, agora sem a presença do parceiro. Os relatos evidenciam a continuidade do cuidado e da atenção materna em 15 das 21 mulheres que têm filhos: "Eu tenho filhos que me adoram. Então, assim eu posso reconstruir, terminar de cuidar os meus filhos" (A20); "Começar uma nova vida com eles (filhos)" (A23). Além disso, as mulheres manifestam desejo de cuidar de si mesmas e desejam assumir uma postura mais ativa nas suas vidas: "Quero me reorganizar, voltar a trabalhar" (A3); "Posso trabalhar. Vou viver assim por quê?" (A10); "Trabalhar, ajudar minha família no que eu posso, e bola pra frente (A14)”. 


\subsubsection{Viver em paz}

As novas perspectivas são importantes para que as mulheres se sintam motivadas, fortifiquem sua decisão de rompimento na relação com o agressor e desejem um futuro diferente. $\mathrm{O}$ desejo por paz também pode ser identificado nas falas: "Viver em paz. Sozinha. Eu e meus cachorros" (A1); "Eu quero chegar na minha casa e ter paz, porque isso eu não tenho há muito tempo. Chegar do serviço, tomar um banho, tomar um café e ficar com os meus filhos. Isso faz muito tempo que eu não tenho. Isso aí não é vida pra ninguém (A24)”.

No estudo de Vieira et al. (2011), foi identificada a expectativa das mulheres de retomarem seus planos e suas vidas após o rompimento com o agressor. Percebese que o desejo de afastamento do agressor favorece o desenvolvimento de novas perspectivas e a esperança de que mudanças ocorram, o que é considerado saudável, uma vez que fortalece aspectos positivos na retomada de planos em suas vidas.

\subsubsection{Permanecer sem companheiro}

Outro desejo mencionado pelas mulheres e destacado como expectativa pessoal é o de permanecer sozinha, sem um parceiro. "Não quero ter ninguém. Já não confio em ninguém. Tenho medo. Medo de me envolver com uma pessoa, e ele (agressor) ir atrás e me perseguir" (A3). "Eu não quero ninguém perto de mim. Eu só quero viver com meu filho. Eu quero que ele fique longe de mim, que me deixe em paz" (A6). "Eu estou muito decepcionada. Não pretendo arrumar companheiro fixo como eu tinha, porque eu vi que nós, mulheres, somos muito vulneráveis" (A12).

$\mathrm{O}$ anseio de não querer mais se envolver com alguém devido ao medo de novas situações de violência a faz preferir ficar sozinha a iniciar um novo relacionamento. De acordo com Fonseca, Ribeiro e Leal (2012), a ideia do casamento sonhado e da relação saudável e duradoura idealizada acaba sendo transformada em decepção, o que, neste estudo, pode estar associado ao desejo de permanecer sozinha. 


\section{CONSIDERAÇÕES FINAIS}

A violência contra a mulher é uma grave violação a seus direitos e afeta, direta ou indiretamente, todo o contexto em que a vítima está inserida e todos aqueles com quem ela convive. Há mulheres em situação de violência que ainda hesitam em realizar a denúncia na DEAM, especialmente devido à vergonha e ao estigma social que atravessam fortemente a violência contra a mulher. A família pode ser um fator de motivação para o rompimento ou um fator de permanência na relação abusiva. Neste estudo, a maior parte das mulheres buscou a DEAM quando os eventos violentos se estenderam aos familiares, especialmente aos filhos. A exposição dos filhos à violência física parece ser o limiar para a denúncia, contudo a violência é multifatorial e não é possível atribuir a revelação a um único fator.

A violência contra a mulher é um crime e deve ser tratada como tal, portanto a existência de um equipamento público específico como a DEAM é fundamental para assegurar os direitos e a proteção. Ainda, o desejo de que o sistema de justiça as mantenha em segurança e distantes do agressor, seja através da prisão ou de medidas protetivas, evidencia que a mulher percebe a violência sofrida também como um problema de segurança pública.

A efetivação da Lei Maria da Penha (Lei n.o 11.340/2006) reafirma a responsabilidade legal do Poder Público na implantação de medidas que visem à garantia da proteção integral às mulheres em situação de violência. Além do sistema de Justiça, cabe destacar o papel de proteção das mulheres por parte da União, Estados e municípios, por meio de serviços especializados de atendimento, criação de casas abrigo e políticas públicas.

Os resultados ainda evidenciam que a mulher desconhece o conjunto de serviços existentes destinados a seu atendimento. É necessário pensar em trabalhos que busquem fortalecer a rede de apoio afetivo e social das mulheres em situação de violência. Para isso, é fundamental a divulgação e melhor articulação entre os serviços de políticas de assistência social e de saúde disponíveis. Destaca-se a necessidade de que os serviços consigam atuar de forma interligada, para receber e acompanhar essas mulheres e, além disso, é de suma importância estimular discussões públicas sobre o tema, desmistificando as crenças sexistas arraigadas historicamente. Afinal, as mulheres em situação de violência precisam ter apoio para enfrentar o problema e saber que podem contar com pessoas significativas em suas vidas e com profissionais preparados para acolhê-las.

A ideia recorrente de ter paz e aproveitar a vida sugere que as mulheres estão em busca de uma saída ou de uma solução que permita experiências saudáveis. 
Diante disso, percebe-se que, no momento do acolhimento, o agressor não foi visto pelas mulheres como fazendo parte de seu futuro. Esse momento seria propício para a atuação conjunta dos serviços de proteção. Uma rede articulada com profissionais capacitados poderia colaborar com a retirada da mulher do isolamento social que assola a maior parte das que estão em situação de violência e poderia contribuir com a manutenção de seus planos de futuro.

Conhecer os motivos que levam a mulher a denunciar a violência e as expectativas nutridas após esse momento de publicização de sua vida permite compreender os fatores que levam a mulher a buscar a DEAM. Esses aspectos são igualmente importantes para identificar os motivos que causam a omissão da denúncia. $O$ estudo evidencia a necessidade de uma atenção integral que favoreça não apenas a revelação, mas o "empoderamento" e a construção de novas perspectivas futuras. Para isso, as políticas públicas devem estar integradas e direcionadas às garantias fundamentais das mulheres, para que, assim, possam se sentir amparadas para realizar a denúncia e fortalecidas para vislumbrar novas perspectivas de vida. 


\section{REFERÊNCIAS}

Barros, E. N., Silva, M. A., Falbo Neto, G. H., Lucena, S. G., Ponzo, L., \& Pimentel, A. P. (2016). Prevalência e fatores associados à violência por parceiro íntimo em mulheres de uma comunidade em Recife/Pernambuco, Brasil. Ciência \& Saúde Coletiva, 21(2), 591-598. Recuperado a partir de http://www. scielo.br/pdf/csc/v21n2/1413-8123-csc-21-02-0591.pdf

Carneiro, A. A., \& Fraga, C. K. (2012). A Lei Maria da Penha e a proteção legal à mulher vítima em São Borja no Rio Grande do Sul: da violência denunciada à violência silenciada. Serviço Social \& Sociedade, 110, 369-397.

Diniz, G. R. S., \& Angelim, F. P. (2003). Violência doméstica: porque é tão difícil lidar com ela? Revista de Psicologia da Unesp, 2(1), 20-35.

Fonseca, D. H., Ribeiro, C. G., \& Leal, N. S. B. (2012). Violência doméstica contra a mulher: realidades e representações sociais. Psicologia \& Sociedade, 24(2), 307-314. Recuperado a partir de http://www.scielo.br/scielo. php?script=sci_arttext\&pid=S0102-71822012000200008

Griebler, C. N., \& Borges, J. L. (2013). Violência contra a mulher: perfil dos envolvidos em boletins de ocorrência da Lei Maria da Penha. Psico, 44(2), $215-$ 225. Recuperado a partir de http://revistaseletronicas.pucrs.br/ojs/index.php/ revistapsico/article/view/11463/9640

Lei no 11.340, de 7 de agosto de 2006. (2006, 7 agosto). Cria mecanismos para coibir a violência doméstica e familiar contra a mulher, nos termos do $₫ 8^{\circ}$ do art. 226 da Constituição Federal, da Convenção sobre a Eliminação de Todas as Formas de Discriminação contra as Mulheres e da Convenção Interamericana para Prevenir, Punir e Erradicar a Violência contra a Mulher; dispóe sobre a criação dos Juizados de Violência Doméstica e Familiar contra a Mulher; altera o Código de Processo Penal, o Código Penal e a Lei de Execução Penal; e dá outras providências. (Lei Maria da Penha). Diário Oficial da União, Brasília. Recuperado a partir de http://www.planalto.gov.br/ccivil_03/_ato20042006/2006/lei/l11340.htm

Lettiere, A., \& Nakano, A. (2011). Violência doméstica: as possibilidades e os limites de enfrentamento. Revista Latino-Americana de Enfermagem, 19(6), 1421-1428. Recuperado a partir de http://www.scielo.br/pdf/rlae/v19n6/ pt_20.pdf 
Lucena, K. D. T., Deininger, L. S. C., Coelho, H. F. C., Monteiro, A. C. C., Vianna, R. P. T., \& Nascimento, J. A. (2016). Análise do ciclo da violência doméstica contra a mulher. Journal of Human Growth and Development, 26(2), 139-146. Recuperado a partir de http://pepsic.bvsalud.org/scielo. php?script=sci_arttext\&pid=S0104-12822016000200003\&lng=pt\&nrm=iso \&tlng=pt

Mahfoud, M. (1987). A vivência de um desafio: plantão psicológico. In R. L. Rosenberg (Org.), Aconselhamento psicológico centrado na pessoa. (pp. 75-83). São Paulo: EPU.

Mendonça, M. F. S., \& Ludermir, A. B. (2017). Violência por parceiro íntimo e incidência de transtorno mental comum. Revista de Saúde Pública, 51(32). Recuperado a partir de http://www.scielo.br/scielo.php?pid=S003489102017000100227\&script=sci_arttext\&tlng=pt

Meneghel, S. N., Mueller, B., Collaziol, M., \& Quadros, M. M. (2013). Repercussões da Lei Maria da Penha no enfrentamento da violência de gênero. Ciência \& Saúde Coletiva, 18(3), 691-700. Recuperado a partir de http://www. scielo.br/scielo.php?script=sci_arttext\&pid=S1413-81232013000300015

Minayo, M. C. S. (Org.). (2015). Pesquisa social: teoria, método e criatividade. Rio de Janeiro: Vozes.

Ministério da Saúde. (2011). Secretaria de Políticas de Saúde. Violência intrafamiliar: orientaçôes para prática em serviço. Brasília: Ministério da Saúde. Recuperado a partir de http://bvsms.saude.gov.br/bvs/publicacoes/cd05_19. pdf

Moré, C. L. O. O. (2015). A "entrevista em profundidade" ou "semiestruturada", no contexto da saúde: dilemas epistemológicos e desafios de sua construção e aplicação. Investigação Qualitativa em Ciências Sociais: Atas CIAIQ, 3, 126-131. Recuperado a partir de http://proceedings.ciaiq.org/index.php/ciaiq2015/ article/view/158/154

Oliveira, C. M., \& Moreira, M. I. C. (2016). Os sentidos produzidos para a violência contra as mulheres a partir da perspectiva dos profissionais da Delegacia Especializada de Atendimento à Mulher de Betim-MG. Psicologia em Revista, 22(3), 729-748. Recuperado a partir de http://periodicos.pucminas.br/index. php/psicologiaemrevista/article/viewFile/12640/11686 
Resolução n. ${ }^{\circ}$ 466, de 12 de dezembro de 2012 (2012, 12 dezembro). Diário Oficial da União, n. 12, 13 junho 2013, seção 1, p. 59.

Romagnoli, R. C., Abreu, L. L. G., \& Silveira, M. F. (2013). A violência contra a mulher em Montes Claros: análise estatística. Gerais: Revista Interinstitucional de Psicologia, 6(2), 282-297. Recuperado a partir de http://pepsic.bvsalud.org/ pdf/gerais/v6n2/v6n2a10.pdf

Romagnoli,R.C.(2015).VáriasMarias: efeitosdaLeiMariadaPenhanasdelegacias. Fractal: Revista de Psicologia, 27(2), 114-122. Recuperado a partir dehttp://www. scielo.br/scielo.php?script=sci_arttext\&pid=S1984-02922015000200114

Sagim, M. B., Biasoli-Alvez, Z., Delfino, V., \& Vanturini, F. (2007). Violência doméstica: a percepção que as vítimas têm de seu parceiro, do relacionamento mantido e das causas da violência. Cogitare Enfermagem, 12(1), 30-36. Recuperado a partir de https://revistas.ufpr.br/cogitare/article/view/8260

Sampieri, R. H., Colado, C. F., \& Lucio, M. P. B. (2013). Metodologia de pesquisa. D. V. Moraes (Trad.), A. G. Q. Garcia, D. Silva, \& M. Júlio (rev. téc.). Porto Alegre: Penso.

Santi, L. N., Nakano, A. M. S., \& Lettiere, A. (2010). Percepção de mulheres em situação de violência sobre o suporte e apoio recebido em seu contexto social. Texto Contexto - Enfermagem, 19(3), 417-424. Recuperado a partir de http://www. scielo.br/scielo.php?script=sci_arttext\&pid=S0104-07072010000300002

Schraiber, L. B., Latorre, M. R. D. O, França Júnior, I., Segri, N. J., \& D'Oliveira, A. F. P. L. (2010). Validade do instrumento Who Vaw Study para estimar violência de gênero contra a mulher. Revista de Saúde Pública, 44(4), 658-666. Recuperado a partir de http://www.scielo.br/scielo.php?script=sci_ arttext\&pid=S0034-89102010000400009

Scorsolini-Comin, F. (2015). Plantão psicológico e o cuidado na urgência: panorama de pesquisas e intervenções. Psico-USF, 20(1), 163-173. Recuperado a partir de http://www.scielo.br/pdf/pusf/v20n1/1413-8271-pusf-20-01-00163. pdf

Silva, L. L., Coelho, E. B. S., \& Caponi, S. N. (2007). Violência silenciosa: violência psicológica como condição da violência física doméstica. Interface, 11(21), 93-103. Recuperado a partir de http://www.scielo.br/scielo. php?script=sci_arttext\&pid=S1414-32832007000100009 
Vieira, L. B., Padoin, S., Souza, I., \& Paulo, C. (2011). Perspectivas para o cuidado de enfermagem às mulheres que denunciam a violência vivida. Escola Anna Nery, 15(4), 678-685. Recuperado a partir de http://www.scielo.br/ scielo.php?script=sci_arttext\&pid=S1414-81452011000400004

World Health Organization. (2013). Global and regional estimates of violence against women: prevalence and health effects of intimate partner violence and non-partner sexual violence. Geneva: WHO. Recuperado a partir de https:// www.who.int/publications/i/item/9789241564625 